\title{
Induction motor performance improvement using twelve sectors DTC and fuzzy logic speed regulation
}

\author{
YASSINE ZAHRAOUI \\ Mohammed 5 University
}

\author{
MOHAMED AKHERRAZ \\ Mohammed 5 University
}

\author{
CHAYMAE FAHASSA \\ Mohammed 5 University
}

Mohammadia School of Engineering Mohammadia School of Engineering Mohammadia School of Engineering Department of Electrical Engineering Department of Electrical Engineering Department of Electrical Engineering Street Ibn Sina, B.P 765 Agdal Rabat Street Ibn Sina, B.P 765 Agdal Rabat Street Ibn Sina, B.P 765 Agdal Rabat MOROCCO MOROCCO MOROCCO zahraoui.yassin@gmail.com akherraz@emi.ac.ma fahassa.chaymae@gmail.com

\begin{abstract}
The direct torque control (DTC) was proposed as an alternative to the vector control in the middle of 1980s. This strategy is based on the direct determination of inverter switching states and offers a simpler scheme and less sensitivity to machine parameters. However, the variable switching frequency of DTC causes high flux and torque ripples which lead to an acoustical noise and degrade the performance of the control scheme, especially at low-speed regions. In the objective of improving the performance of DTC for the induction motor, a fuzzy logic based non-linear speed controller is inserted to ensure a robust control against different uncertainties and external disturbances. Moreover, the sensorless control can increase the reliability and decrease the cost of the control system.Therefore, afuzzyadaptiveLuenbergerobserverisusedtoimprovethespeedandthefluxestimation.
\end{abstract}

Key-Words: Twelve sectors DTC, Fuzzy logic controller, Adaptive Luenberger observer, Fuzzy adaptation mechanism

Received: August 19, 2019. Revised: February 20, 2020. Accepted: March 13, 2020. Published: March 24, 2020.

\section{Introduction}

Nowadays, the AC machines have replaced the DC machines in industry applications because of their advantages, such as, the reliability and the lack of commutator and brushes which make them able to work under unfriendly conditions. The most popular $\mathrm{AC}$ machines are the induction motors (IMs) and the permanent magnet synchronous motors (PMSMs). They are used in various industrial applications, electric vehicles (EV), tools and drives etc. The squirrel cage induction motor in particular, is widely used due to its reduced cost and lower maintenance requirement [1].

The Direct Torque Control (DTC) guarantees a separated flux and torque control. It was introduced by Takahashi and Nagochi in the middle of 1980s in Japan [2], and also in Germany by Depenbrock under the name of Direct Self-Control (DSC) [3]. In contrast to FOC, this control is completely done in stationary frame (stator fixed coordinates). Furthermore, DTC generates the inverter gating signals directly through a look up switching table and the use of modulator is not necessary. It offers an excellent torque response using less model's parameters than FOC. Due to its simplicity and very fast response it can be so applicable for high performance drive applications [4]. However, the standard DTC method suffers from high flux and torque ripples owing to the use of hysteresis controllers. Many modified DTC schemes have been proposed in order to reduce ripples [5].

Moreover, the sensorless control is another major issue in control domain. The developed control schemes using advanced strategies such as non-linear techniques require an accurate speed and flux measurement or estimation for closed loop control design. The use of sensors has several downsides like high cost, fragility and low reliability [6]. Furthermore, the physical environment sometimes, does not allow to use sensors. Due to the multiple variables and nonlinearity of induction motor dynamics, the estimation of the speed and the flux without the measurement is still a very challenging subject. Various sensorless approaches have been proposed in the literature. We mentioned among of them, the deterministic adaptive observers [7], stochastic extended Kalman filter (EKF) [8] and model reference adaptive system (MRAS) [9]. Aside from the control design, the sliding mode theory proves its worth in estimation also in diverse structures of sliding mode observers [10].

Generally, the control and estimation of induction machines in variable speed operation is more compli- 
cate than DC machines. The main reasons that they have more complex dynamic and they more request of complicated calculations.

\section{Induction motor drive modelling}

The mathematical model of a three-phase squirrel cage IM drive in $\alpha-\beta$ reference frame is:

$$
\left\{\begin{array}{l}
\dot{x}=\mathbf{A} x+\mathbf{B} u \\
y=\mathbf{C} x
\end{array}\right.
$$

Where $x, u$ and $y$ are the state, the input and the output vector respectively.

$x=\left[\begin{array}{llll}i_{s \alpha} & i_{s \beta} & \phi_{r \alpha} & \phi_{r \beta}\end{array}\right]^{t} ; u=\left[\begin{array}{ll}u_{s \alpha} & u_{s \beta}\end{array}\right]^{t} ; y=\left[\begin{array}{ll}i_{s \alpha} & i_{s \beta}\end{array}\right]^{t}$

$$
\begin{gathered}
\mathbf{A}=\left[\begin{array}{cccc}
-\lambda & 0 & \frac{K}{T_{r}} & K \omega_{r} \\
0 & -\lambda & -K \omega_{r} & \frac{K}{T_{r}} \\
\frac{L_{m}}{T_{r}} & 0 & -\frac{1}{T_{r}} & -\omega_{r} \\
0 & \frac{L_{m}}{T_{r}} & \omega_{r} & -\frac{1}{T_{r}}
\end{array}\right] \\
\mathbf{B}=\left[\begin{array}{cc}
\frac{1}{\sigma L_{s}} & 0 \\
0 & \frac{1}{\sigma L_{s}} \\
0 & 0 \\
0 & 0
\end{array}\right] \quad \mathbf{C}=\left[\begin{array}{cccc}
1 & 0 & 0 & 0 \\
0 & 1 & 0 & 0
\end{array}\right] \\
\quad \text { With } \\
\lambda=\frac{R_{s}}{\sigma \cdot L_{s}}+\frac{1-\sigma}{\sigma \cdot T_{r}} ; K=\frac{1-\sigma}{\sigma \cdot L_{m}} ; \sigma=1-\frac{L_{m}^{2}}{L_{s} \cdot L_{r}} ; T_{r}=\frac{L_{r}}{R_{r}}
\end{gathered}
$$

Figure 1 shows the state space mathematical model of the induction motor drive.

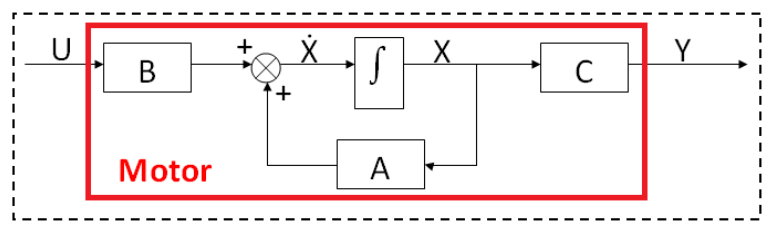

Figure 1: State space mathematical model of the IM

\section{DTC principle}

The DTC achieves a decoupled control of the stator flux and the torque in the stationary frame $(\alpha, \beta)$. It uses a switching table for the selection of an appropriate voltage vector. The selection of the switching states is related directly to the variation of the stator flux and the torque of the machine. Hence, the selection is made by restricting the flux and torque magnitudes within two hysteresis bands. Those controllers ensure a separated regulation of both of these quantities. The inputs of hysteresis controllers are the flux and the torque errors as well as their outputs determine the appropriate voltage vector for each commutation period [11].

\subsection{Stator flux and torque control}

\subsubsection{Stator flux control}

Basing on the IM model in stationary frame, the stator flux equation can be expressed as follows:

$$
\dot{\phi}_{s}=V_{s}-R_{s} i_{s}
$$

So:

$$
\phi_{s}(t)=\int_{0}^{T_{z}}\left(V_{s}-R_{s} i_{s}\right) d t+\phi_{s}(0)
$$

$\phi_{s}(0)$ is the flux vector at instant $t=0$ and $T_{z}$ is the sampling period.

By applying a non-zero vector during $T_{z}$, we can neglect the stator resistance voltage drop $R_{s} i_{s}$ compared to $V_{s}$ for high speed regions. Then Equation (3) can be written as:

$$
\phi_{s}(t) \approx V_{s} T_{z}+\phi_{s}(0)
$$

The relation between the stator voltage and the stator flux change can be established as:

$$
\Delta \phi_{s}=\phi_{s}(t)-\phi_{s}(0)=V_{s} T_{z}
$$

The Equation (5) means that the stator flux can be changed by the application of stator voltage during a time $T_{z}$. The stator flux vector's extremity moves in a direction given by the voltage vector and making a circular trajectory as shown in Figure 2 [12].
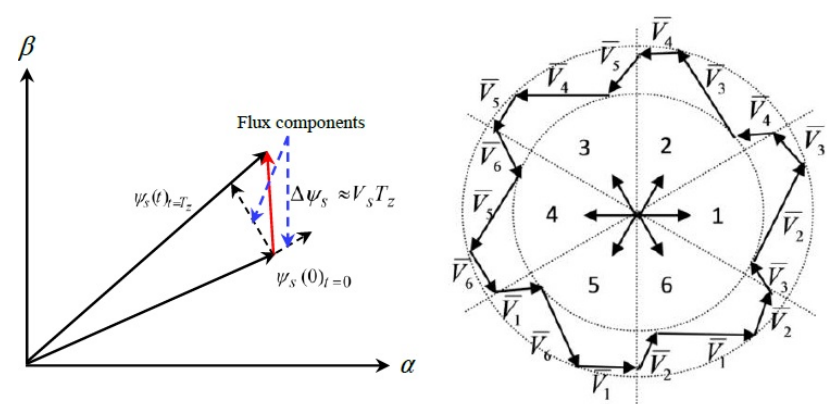

Figure 2: Evolution of stator flux vector in the complex plan

\subsubsection{Torque control}

During one sampling period, the rotor flux vector is supposed invariant. The torque of induction motor can be expressed in terms of stator and rotor flux vectors as follows:

$$
\begin{gathered}
T_{e}=p \frac{M_{s r}}{\sigma L_{s} L_{r}} \phi_{s} \times \phi_{r} \\
\left|T_{e}\right|=p \frac{M_{s r}}{\sigma L_{s} L_{r}}\left|\phi_{s}\right|\left|\phi_{r}\right| \sin (\delta)
\end{gathered}
$$


Where $p$ is the number of pole pairs and $\phi_{s}, \phi_{r}$ are stator and rotor flux vectors, $\delta$ is the angle between the stator and rotor flux vectors.

From expression (7), it is clear that the torque is controlled by the stator and rotor flux amplitudes. If those quantities are maintaining constant, the torque can be controlled by adjusting the load angle $\delta$.

\subsection{Stator flux estimation}

The estimation of the stator flux is usually done by the integration of the back-emf (Electromotive force). The stator flux components can be expressed using stator voltages and currents in the stationary reference frame $(\alpha, \beta)$ by:

$$
\left\{\begin{array}{l}
\phi_{s \alpha}=\int_{0}^{t}\left(V_{s \alpha}-R_{s} i_{s \alpha}\right) d t \\
\phi_{s \beta}=\int_{0}^{t}\left(V_{s \beta}-R_{s} i_{s \beta}\right) d t
\end{array}\right.
$$

The stator flux magnitude and flux angle can then be computed as:

$$
\begin{gathered}
\left|\phi_{s}\right|=\sqrt{\phi_{s \alpha}^{2}+\phi_{s \beta}^{2}} \\
\theta_{s}=\tan ^{-1}\left(\frac{\phi_{s \beta}}{\phi_{s \alpha}}\right)
\end{gathered}
$$

\section{Twelve sectors DTC strategy}

\subsection{Methods}

Due to the limits of the conventional DTC strategy, especially the high torque and flux ripples problem, various control structures are presented to improve the performances of DTC. The twelve sectors DTC based on an extended switching table and the constant switching frequency is a well discussed solution [13]. In the conventional six sectors DTC, two switching states per sector are not considered which presents an ambiguity in torque control. A sector shifting takes the first sector from 0 to $\frac{\pi}{3}$ instead of $\frac{11 \pi}{6}$ to $\frac{\pi}{6}$ that provides a new switching table. However, in a similar way, it has two unused vectors per sector also (i.e. $V_{i+2}$ and $V_{i-1}$ ) which present an ambiguity in flux instead of torque. Another strategy divides the circular flux locus into 12 sectors instead of 6 as shown in Figure 3 [13]. This makes all the six states used per sector. In twelve sectors DTC, the vector $V_{1}$ produces a large increase in flux and a small increase in torque for the sector 12 . On the contrary, $V_{2}$ produces a large increase in torque and small in flux. We can deduce that it is necessary to define now small and large torque variations. This requires to divide the hysteresis band of the torque into four parts. Then, a twelve-sectors

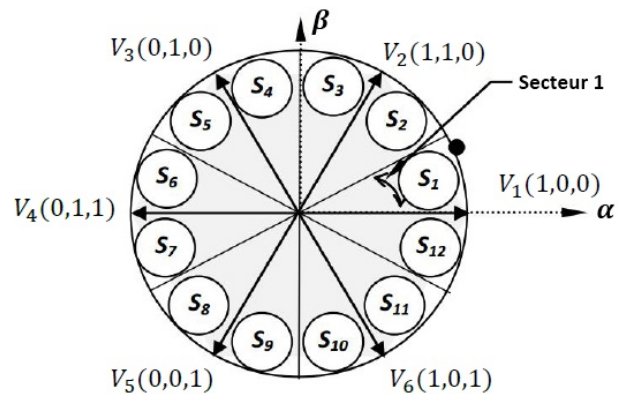

Figure 3: Voltage space vector in twelve sectors case

look-up table is provided as shown in Table 1 below. Considerable studies in literature mentioned that the increasing of the number of the sectors have a slight effect on reducing the high ripples and current harmonics. In addition, the twelve sectors DTC provides good dynamic in high and low speed regions [12][13].

\subsection{Speed regulation in 12-sectors DTC strategy}

DTC strategy has the ability to operate even without a speed regulation loop, so it does not require any information about rotor speed. This can classify DTC as a speed sensorless strategy for many industrial applications. Otherwise, to achieve an adjustable speed control, a speed controller is necessary to have a speed regulation and to generate the reference of electromagnetic torque. Commonly, the proportionalintegral (PI) controllers are used for the regulation. The fuzzy controller is performed by comparing the speed reference signal to the actual measured speed value. Then the comparison error becomes the input of the PI [14]. Generally, the design of a fuzzy regulator requires the choice of the following parameters: linguistic variables, membership functions, inference method and defuzzification strategy. With:

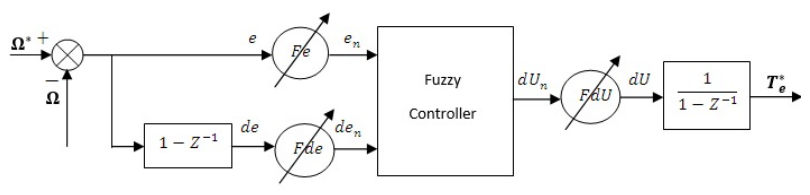

Figure 4: Speed fuzzy controller structure

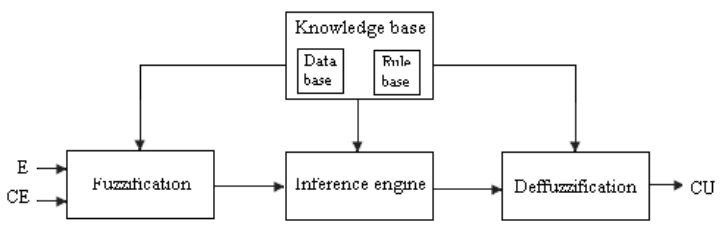

Figure 5: Block diagram of a fuzzy logic controller 
Table 1: Look up switching table with twelve sectors

\begin{tabular}{|c|c|c|c|c|c|c|c|c|c|c|c|c|c|}
\hline$\phi_{s}$ & $T_{s}$ & $S_{1}$ & $S_{2}$ & $S_{3}$ & $S_{4}$ & $S_{5}$ & $S_{6}$ & $S_{7}$ & $S_{8}$ & $S_{9}$ & $S_{10}$ & $S_{11}$ & $S_{12}$ \\
\hline \multirow{4}{*}{1} & 2 & $V_{2}$ & $V_{3}$ & $V_{3}$ & $V_{4}$ & $V_{4}$ & $V_{5}$ & $V_{5}$ & $V_{6}$ & $V_{6}$ & $V_{1}$ & $V_{1}$ & $V_{2}$ \\
& 1 & $V_{2}$ & $V_{2}$ & $V_{3}$ & $V_{3}$ & $V_{4}$ & $V_{4}$ & $V_{5}$ & $V_{5}$ & $V_{6}$ & $V_{6}$ & $V_{1}$ & $V_{1}$ \\
& -1 & $V_{1}$ & $V_{1}$ & $V_{2}$ & $V_{2}$ & $V_{3}$ & $V_{3}$ & $V_{4}$ & $V_{4}$ & $V_{5}$ & $V_{5}$ & $V_{6}$ & $V_{6}$ \\
& -2 & $V_{6}$ & $V_{1}$ & $V_{1}$ & $V_{2}$ & $V_{2}$ & $V_{3}$ & $V_{3}$ & $V_{4}$ & $V_{4}$ & $V_{5}$ & $V_{5}$ & $V_{6}$ \\
\hline \multirow{4}{*}{0} & 2 & $V_{3}$ & $V_{4}$ & $V_{4}$ & $V_{5}$ & $V_{5}$ & $V_{6}$ & $V_{6}$ & $V_{1}$ & $V_{1}$ & $V_{2}$ & $V_{2}$ & $V_{3}$ \\
& 1 & $V_{4}$ & $V_{4}$ & $V_{5}$ & $V_{5}$ & $V_{6}$ & $V_{6}$ & $V_{1}$ & $V_{1}$ & $V_{2}$ & $V_{2}$ & $V_{3}$ & $V_{3}$ \\
& -1 & $V_{5}$ & $V_{5}$ & $V_{6}$ & $V_{6}$ & $V_{1}$ & $V_{1}$ & $V_{2}$ & $V_{2}$ & $V_{3}$ & $V_{3}$ & $V_{4}$ & $V_{4}$ \\
& -2 & $V_{5}$ & $V_{6}$ & $V_{6}$ & $V_{1}$ & $V_{1}$ & $V_{2}$ & $V_{2}$ & $V_{3}$ & $V_{3}$ & $V_{4}$ & $V_{4}$ & $V_{5}$ \\
\hline
\end{tabular}

$$
\begin{gathered}
e_{k}=\Omega_{k}^{*}-\Omega_{k-1} \\
d e_{k}=\frac{e_{k}-e_{k-1}}{T_{s}} \\
T_{e_{k}}^{*}=T_{e_{k-1}}^{*}-d U_{k}
\end{gathered}
$$

$e_{\Omega n}=K_{e \Omega} e_{\Omega} ; d e_{\Omega n}=K_{d e \Omega} d e_{\Omega} ; d U_{n}=K_{u \Omega} d U$ Symmetrical triangular membership functions with 7 fuzzy sets are used for the input and output variables as shown in Figures 6,7 and 8. The linguistic vari-

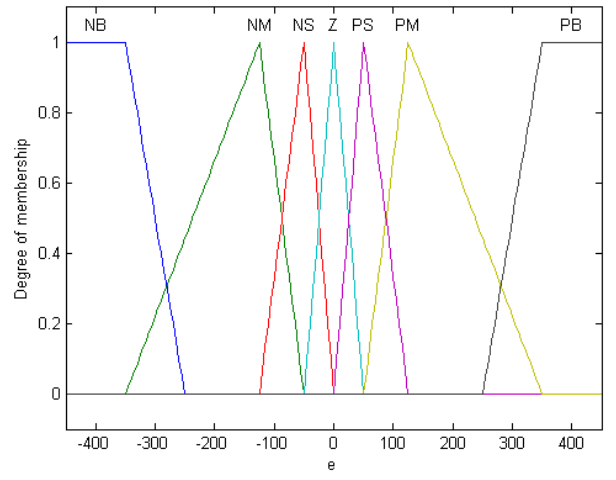

Figure 6: Error membership function $e_{n}$

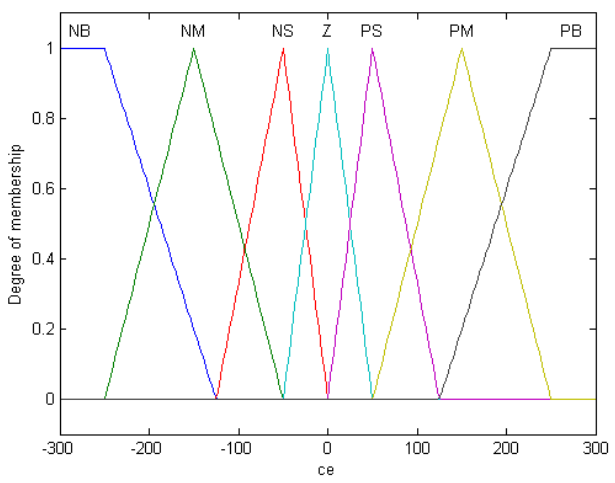

Figure 7: Error variation membership function $d e_{n}$

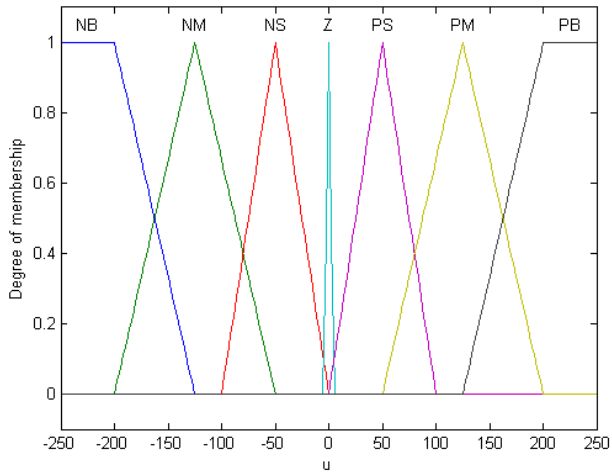

Figure 8: Output membership function $d U_{n}$

ables are defined as follows: NB (Negative Big), NM (Negative Medium), NS (Negative Small), Z (Zero), PS (Positive Small), PM (Positive Medium), PB (Positive Big). The fuzzy rules, used to determine the regulator's output variable, are deduced from a table called the inference table. In this case, $7 \times 7=49$ rules as shown in table 2. This inference matrix is established

Table 2: Inference matrices

\begin{tabular}{|c|c|c|c|c|c|c|c|}
\hline e/ce & $N B$ & $N M$ & $N S$ & $Z$ & $P S$ & $P M$ & $P B$ \\
\hline$P B$ & $Z$ & $P S$ & $P M$ & $P B$ & $P B$ & $P B$ & $P B$ \\
\hline$P M$ & $N S$ & $Z$ & $P S$ & $P M$ & $P B$ & $P B$ & $P B$ \\
\hline$P S$ & $N M$ & $N S$ & $Z$ & $P S$ & $P M$ & $P B$ & $P B$ \\
\hline$Z$ & $N B$ & $N M$ & $N S$ & $Z$ & $P S$ & $P M$ & $P B$ \\
\hline$N S$ & $N B$ & $N B$ & $N M$ & $N S$ & $Z$ & $P S$ & $P M$ \\
\hline$N M$ & $N B$ & $N B$ & $N B$ & $N M$ & $N S$ & $Z$ & $P S$ \\
\hline$N B$ & $N B$ & $N B$ & $N B$ & $N B$ & $N M$ & $N S$ & $Z$ \\
\hline
\end{tabular}

on the basis of a perfect knowledge of the behaviour of the system to be adjusted, as well as knowledge of the objective of the control to be achieved. The method of inference used in this work is Mamdani's method whose fuzzy rule which connects the output with the inputs is of the kind: 
if $e_{n}$ is NS and $d e_{n}$ is NM so $d U_{n}$ is NB

Once the fuzzy output is calculated, it must be transformed into a physical value, this is the role of the defuzzification interface. In this work, we take as a defuzzification criterion the method of the center of gravity which allows to express analytically the output of the fuzzy regulator, to simplify its implementation and to reduce the calculation time. In this case, the abscissa of the center of gravity corresponding to the output of the fuzzy regulator of the Mamdani type is given by the following relation:

$$
d U_{n}=\frac{\int x \mu_{R}(x) d x}{\int \mu_{R}(x) d x}
$$

\section{Fuzzy adaptive Luenberger ob- server for flux and speed estima- tion}

The adaptive flux observer is a deterministic type of observers based on a deterministic model of the system [15]. In this work, the adaptive Luenberger state observer (ALO) is used to estimate the flux components and the rotor speed by including an adaptive mechanism based on the Lyapunov theory and fuzzy regulation. In general, the equations of the ALO can be expressed as follow:

$$
\left\{\begin{array}{l}
\hat{\dot{x}}=\mathbf{A} \hat{x}+\mathbf{B} u+\mathbf{L}(y-\hat{y}) \\
\hat{y}=\mathbf{C} \hat{x}
\end{array}\right.
$$

The symbol` denotes the estimated value and $\mathbf{L}$ is the observer gain matrix. The mechanism of adaptation speed is deduced by Lyapunov theory. The estimation error of the stator current and rotor flux, which is the difference between the observer and the model of the motor, is given by:

$$
\dot{e}=(\mathbf{A}-\mathbf{L C}) e+\Delta \mathbf{A} \hat{x}
$$

Where $e=x-\hat{x}$

$$
\Delta \mathbf{A}=\mathbf{A}-\tilde{\mathbf{A}}=\left[\begin{array}{cccc}
0 & 0 & 0 & K . \Delta \omega_{r} \\
0 & 0 & -K . \Delta \omega_{r} & 0 \\
0 & 0 & 0 & -\Delta \omega_{r} \\
0 & 0 & \Delta \omega_{r} & 0
\end{array}\right]
$$

$$
\Delta \omega_{r}=\omega_{r}-\hat{\omega}_{r}
$$

Definition 1 We consider the following Lyapunov function:

$$
V=e^{t} \cdot e+\frac{\left(\Delta \omega_{r}\right)^{2}}{\lambda}
$$

Where $\lambda$ is a positive coefficient, its derivative is given as follow:

$$
\begin{array}{r}
\dot{V}=e^{t}\left[(\mathbf{A}-\mathbf{L} \mathbf{C})^{t}+(\mathbf{A}-\mathbf{L} \mathbf{C})\right] e \\
-2 K \Delta \omega_{r}\left(e_{i_{s \alpha}} \hat{\phi_{r \beta}}-e_{i_{s \beta}} \hat{\phi_{r \alpha}}\right)+\frac{2}{\lambda} \Delta \omega_{r} \dot{\hat{\omega}_{r}}
\end{array}
$$

With $\hat{\omega}_{r}$ is the estimated rotor speed. The adaptation law for the estimation of the rotor speed can be deduced by the equality between the second and third terms of Equation (19):

$$
\hat{\omega}_{r}=\int \lambda K\left(e_{i_{s \alpha}} \hat{\phi}_{r \beta}-e_{i_{s \beta}} \hat{\phi}_{r \alpha}\right) d t
$$

The feedback gain matrix $\mathbf{L}$ is chosen to ensure the fast and robust dynamic performance of the closed loop observer.

$$
\mathbf{L}=\left[\begin{array}{cc}
l_{1} & -l_{2} \\
l_{2} & l_{1} \\
l_{3} & -l_{4} \\
l_{4} & l_{3}
\end{array}\right]
$$

With $l_{1}, l_{2}, l_{3}$ and $l_{4}$ are given by: $l_{1}=\left(k_{1}-1\right)\left(\gamma+\frac{1}{T_{r}}\right) ; l_{2}=-\left(k_{1}-1\right) \hat{\omega}_{r}$ $l_{3}=\frac{\left(k_{1}^{2}-1\right)}{K}\left(\gamma-K \cdot \frac{L_{m}}{T_{r}}\right)+\frac{\left(k_{1}-1\right)}{K}\left(\gamma+\frac{1}{T_{r}}\right) ;$ $l_{4}=-\frac{\left(k_{1}-1\right)}{K} \cdot \hat{\omega}_{r}$

Remark $2 k_{1}$ is a positive coefficient obtained by pole placement approach; a wise choice was made for its value which is 1.06 in order to guarantee a fast response. Fuzzy logic control (FLC) in adaptation mechanism replaces conventional control and it gives robust performance against parameter variation and machine saturation [16].

The state space mathematical model of the adaptive observer is illustrated by Figure 9 .

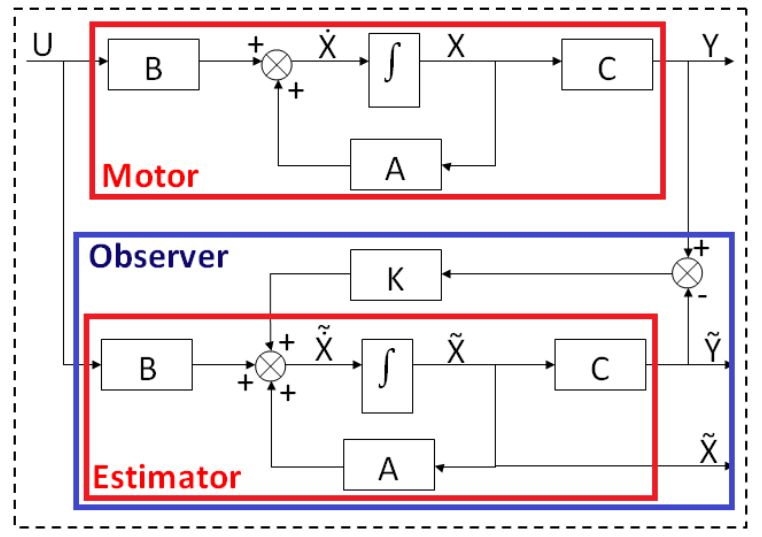

Figure 9: State space model of the observer

Figure 10 shows the overall structure of the proposed DTC strategy. 


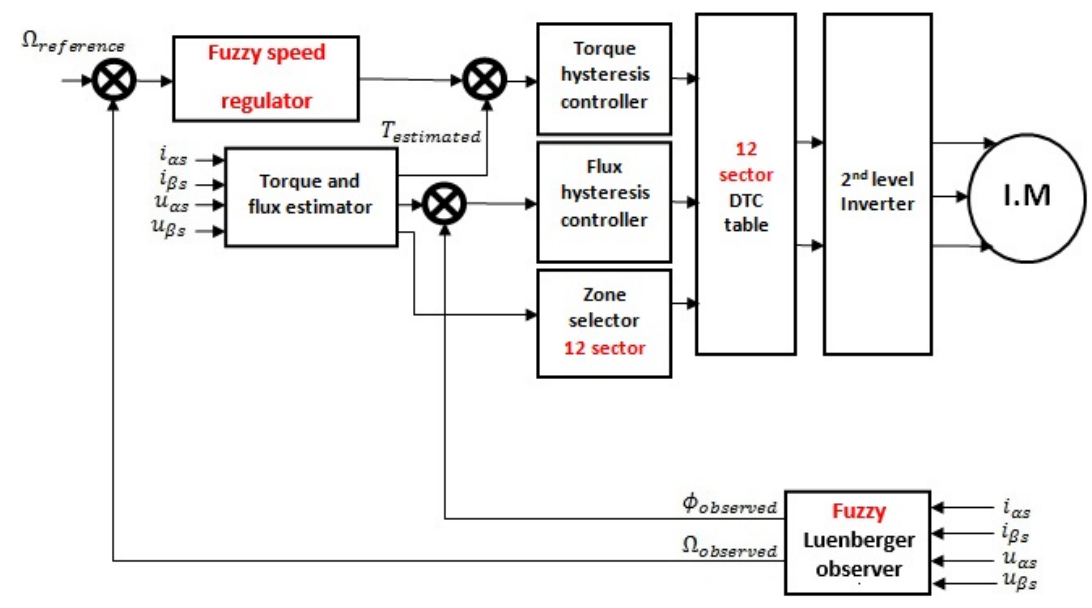

Figure 10: Proposed control scheme

\section{Results and discussion}

A series of simulation tests were carried out on the proposed system. During all the tests, the reference of the stator flux is set to $1 \mathrm{~Wb}$. In the first test, The step reference is chosen because it is the hardest for most control processes, and it allows to determine the system exact response time. A sudden load of 10 N.m is applied at instant $0.2 s$ and removed at $1.8 \mathrm{~s}$ in order to test the system stability. In the second test, the system will be operated at very low speed region.

Figure 11 shows the torque THD coefficient for the proposed and conventional DTC. It is reduced from $64.21 \%$ to $54.03 \%$ which means that the torque ripples are much lower with the proposed DTC. Figure 12 shows the stator flux THD coefficient for the proposed and conventional DTC. It has been reduced from $63.56 \%$ to $56.00 \%$ which also means that the flux ripples are much lower with the 12-sectors DTC. The switching frequency of the proposed DTC is constant, the reason is that each inverter's interrupter has a rest moment (switching off) which can reduce the commutation losses even in steady state or in transient operation.

Figure 13 (a) shows that the steady state is reached quickly and the starting torque and currents reach maximum values and are stabilized at the same time, the starting torque is high in order to overcome the inertia and friction and the dynamics of speed are very fast with a short response time. This means the high performance of the flux and torque estimators, especially the speed fuzzy regulator. The response time is very little $0.02 s$ and there is no overshoot of the reference speed. The system rejects quickly the load perturbation even it is applied for almost the entire simulation interval.

Figure 13 (e) shows that the torque is reacting quickly to the speed transition and to the load. It does not ex- ceed $25 N$. $m$ even in the rotation sense inversion. The applied load is clearly shown between $0.2 s$ and $1.8 s$. The speed error does not exceed $0.25 \mathrm{rad} / \mathrm{s}$, the flux error is very little and does not exceed $1.5 \mathrm{~Wb}$. That means the high performance of the observer in speed and flux tracking. The fuzzy adaptation mechanism rejects any external perturbation very quickly.

Figure $13(\mathrm{~g})$ shows the 12 -sectors DTC zone selection high performance, and the flux crown does not exceed 1 in radius, Figure 13 (h). That also demonstrates the system high performance.

In the second test of Figure 14, the control system kept the same good performance even the speed region is very low this time. The speed error is very little and the stator flux is tracking the reference very well. The 3-phase stator currents magnitude is high at the starting, and then it decreases quickly to reach a constant value. The zone selection is quick and the flux crown is perfect.

\section{Conclusion}

12-sectors DTC for a 3-phase induction motor drive is designed and simulated in MATLAB/Simulink, and it's dynamic performance is studied too. The starting current, fuzzy speed regulation, flux distortion and torque pulsation are much better with the proposed technique. The simulated responses show that the system performance is good during the instant load, the simulated current and torque during the steady state are improved, with faster dynamic characteristic.

The modified DTC showed a reducer flux ripples, faster magnitude tracking at the starting up and better components waveform than the conventional DTC. In conclusion, 12-sectors technique has proved good performance dynamic especially at very low speed. 


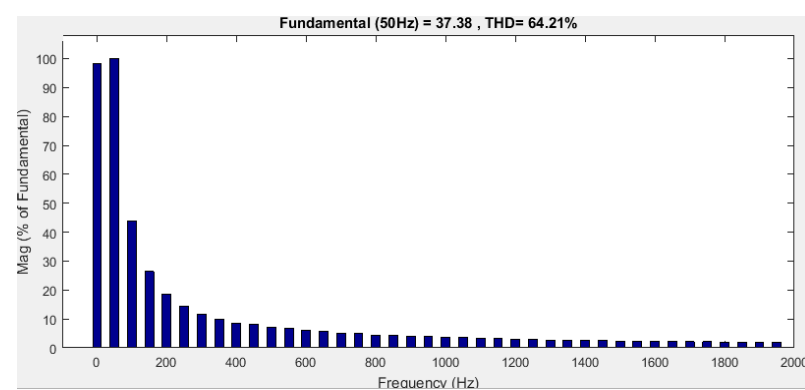

(a) Conventional DTC

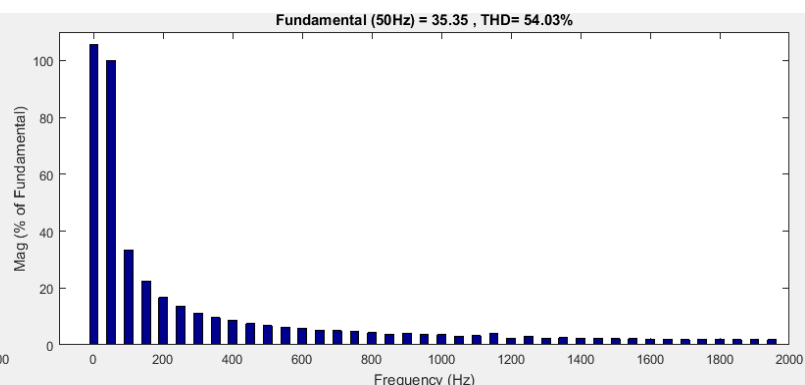

(b) Proposed DTC

Figure 11: Torque THD improvement

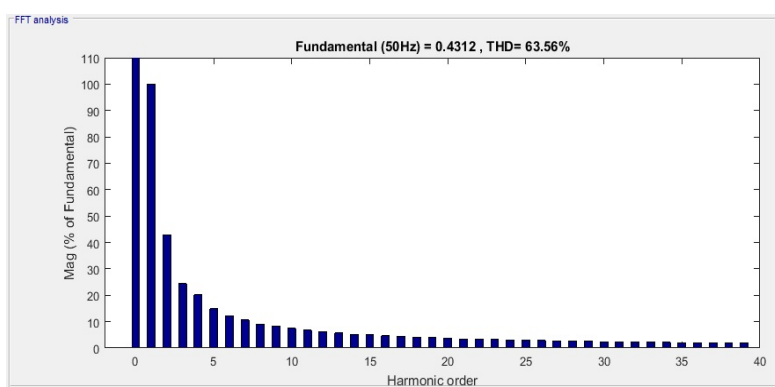

(a) Conventional DTC

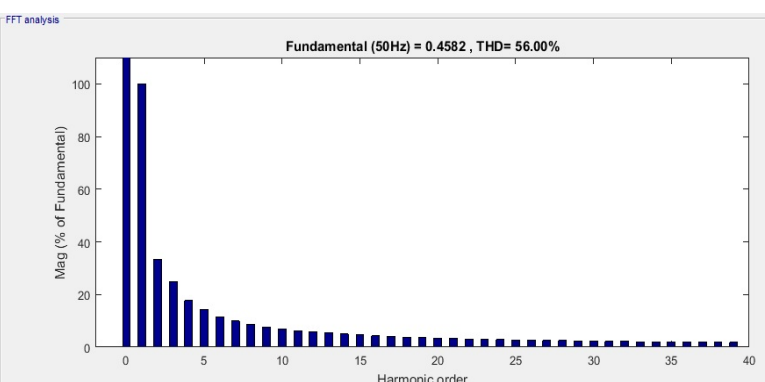

(b) Proposed DTC

Figure 12: Flux THD improvement

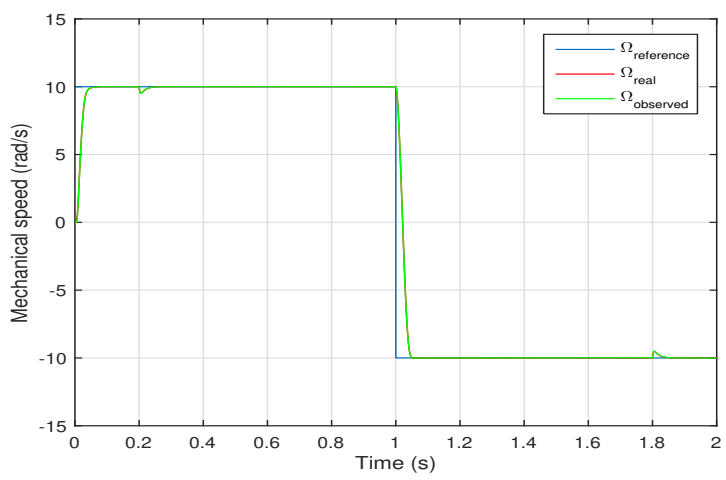

(a) Mechanical speed

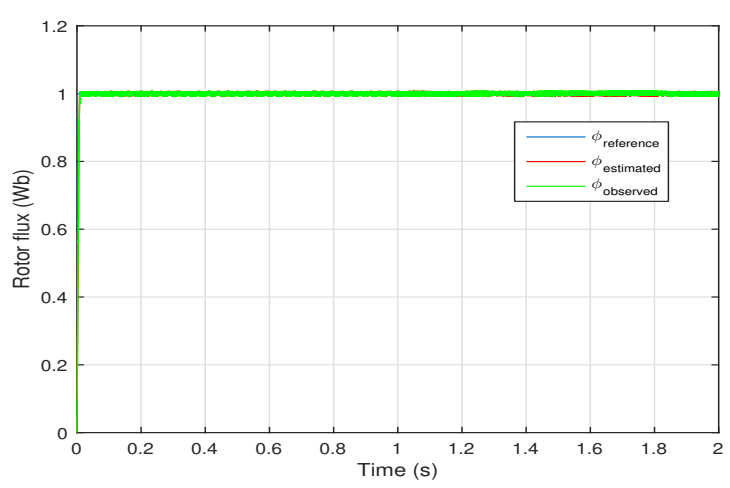

(c) Stator flux

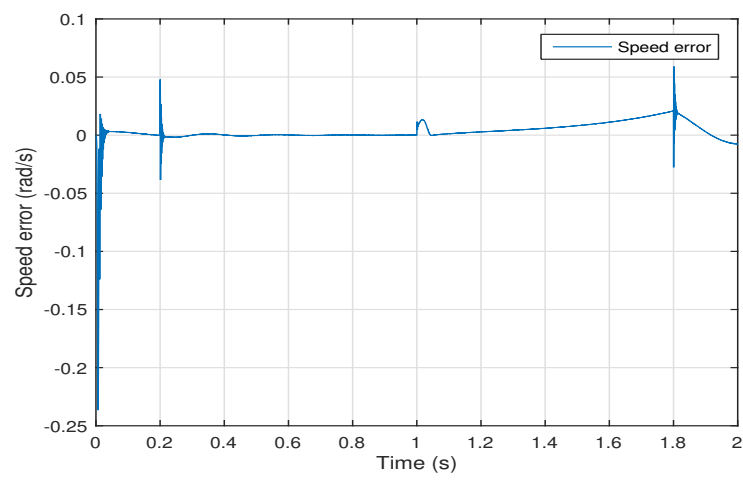

(b) Speed error

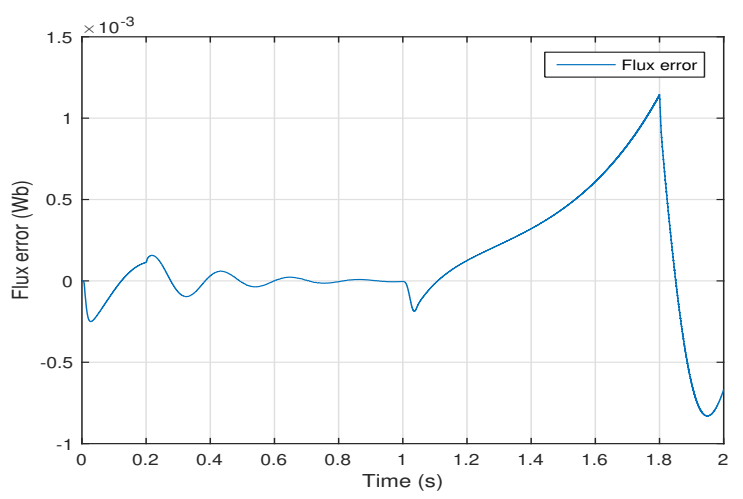

(d) Flux error 


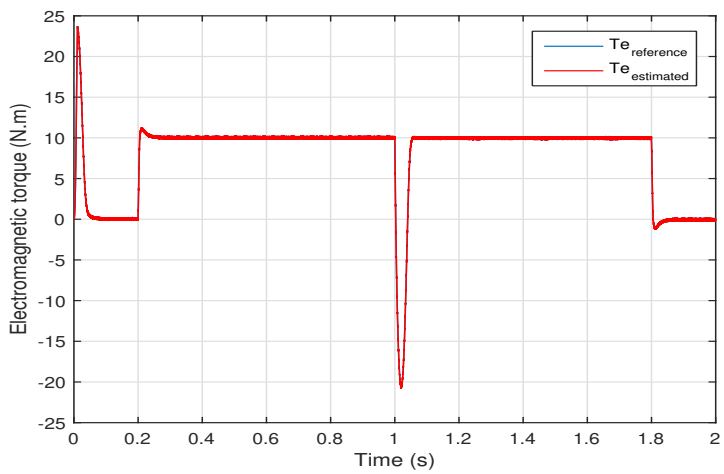

(e) Electromagnetic torque

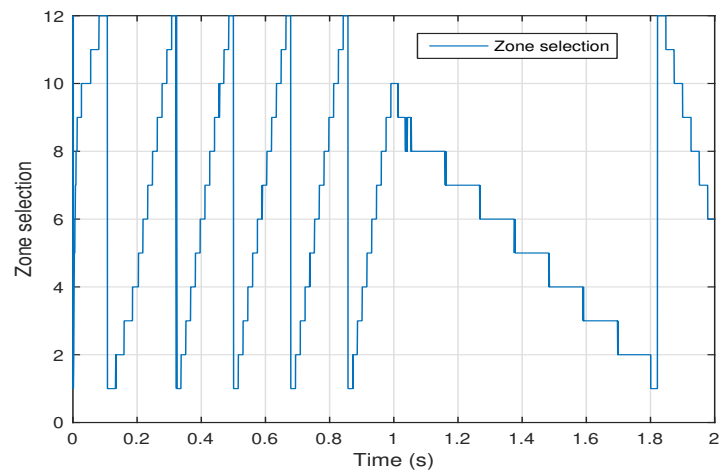

(g) Zone selection

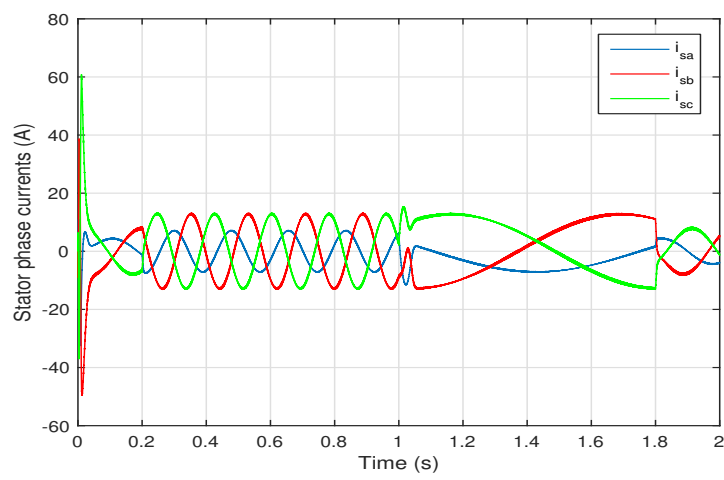

(f) Stator phase currents

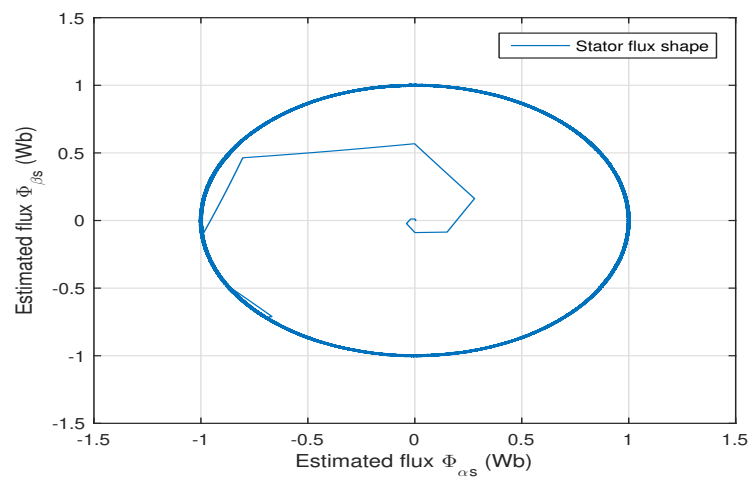

(h) Flux shape

Figure 13: Steady state with load application

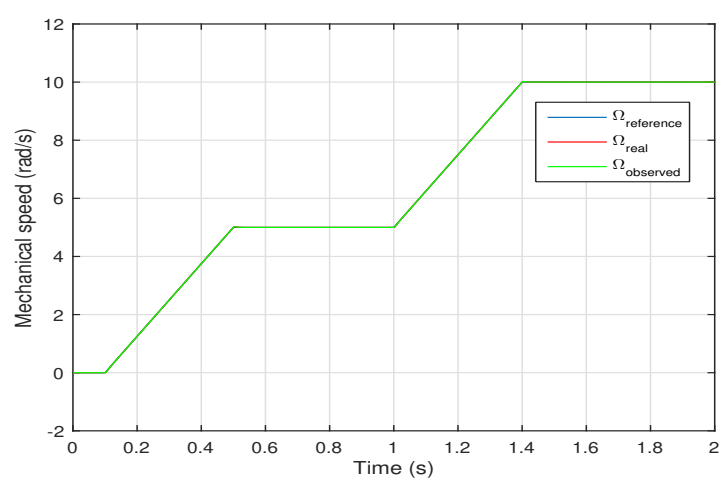

(a) Mechanical speed

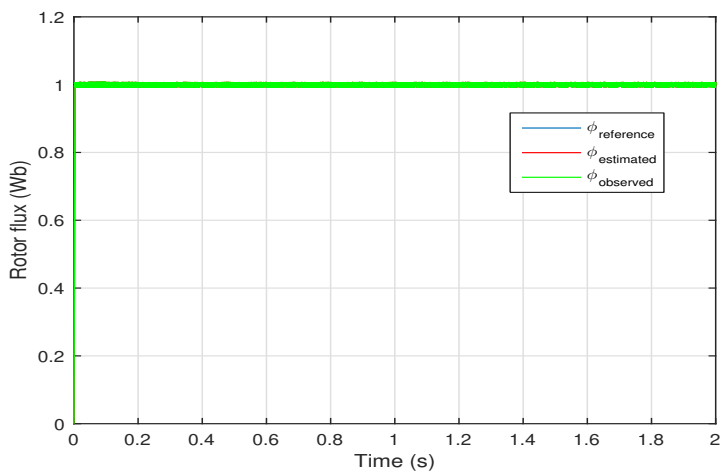

(c) Stator flux

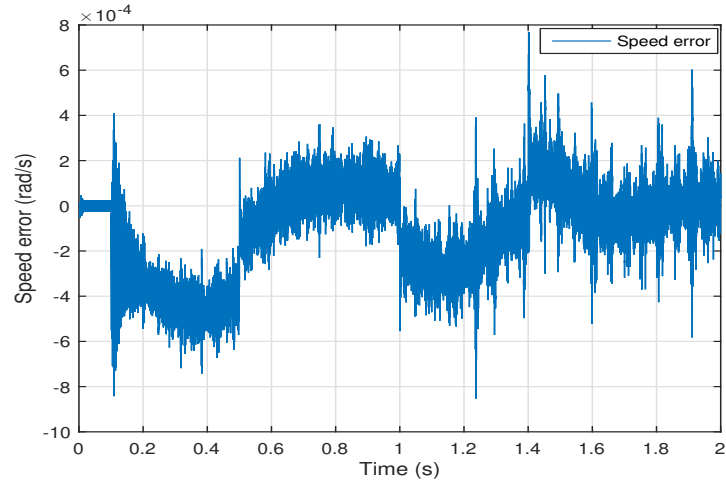

(b) Speed error

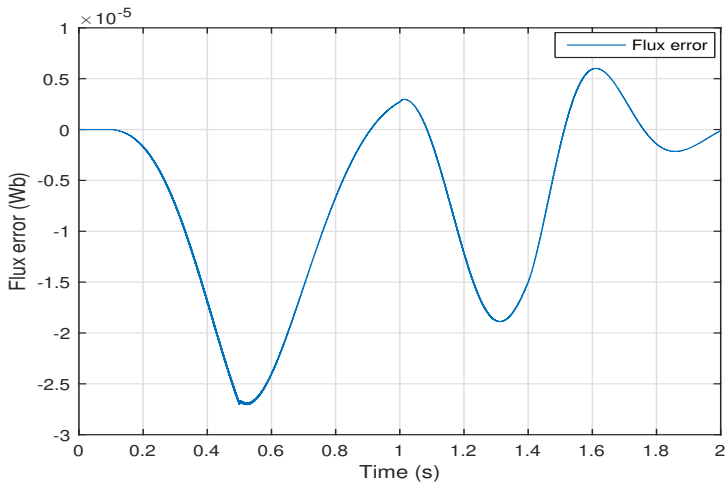

(d) Flux error 


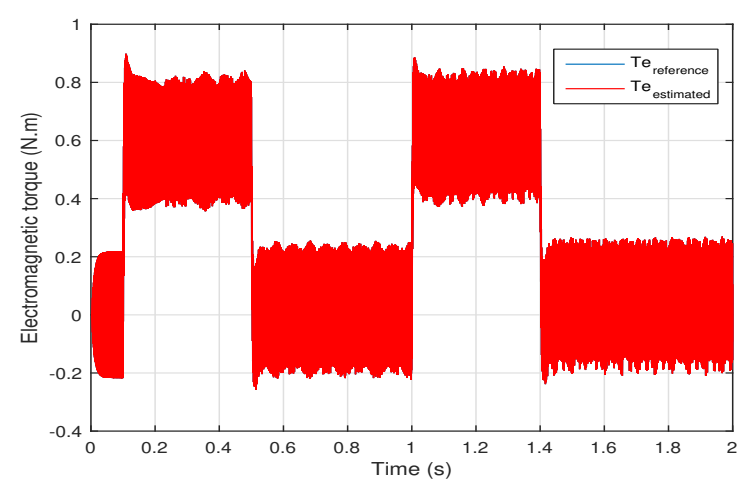

(e) Electromagnetic torque

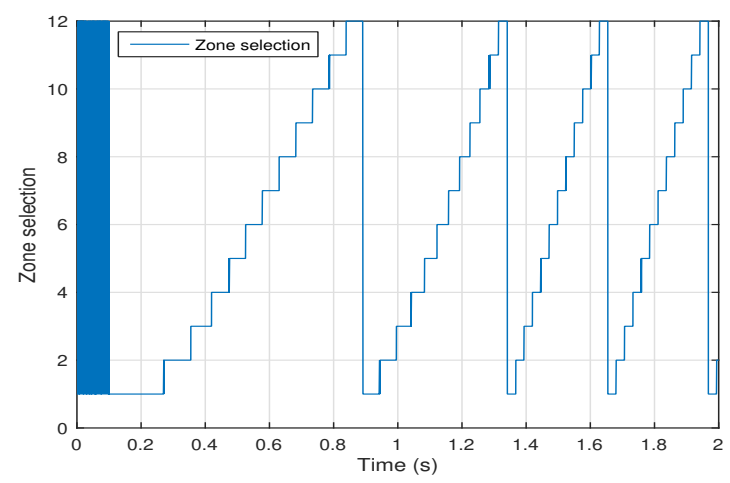

(g) Zone selection

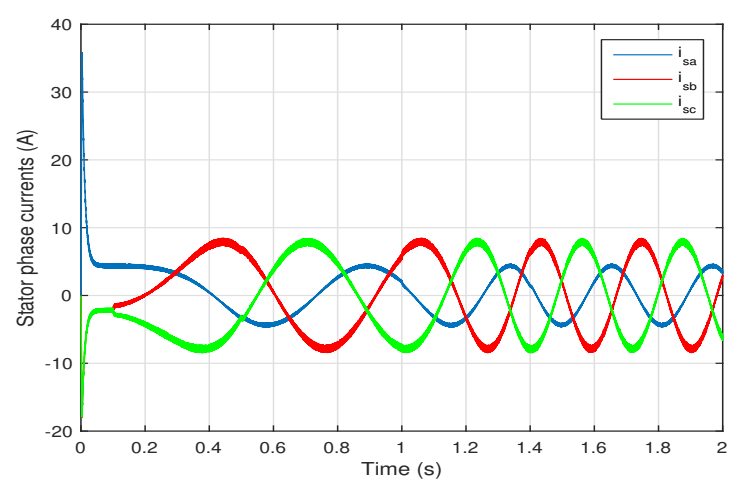

(f) Stator phase currents

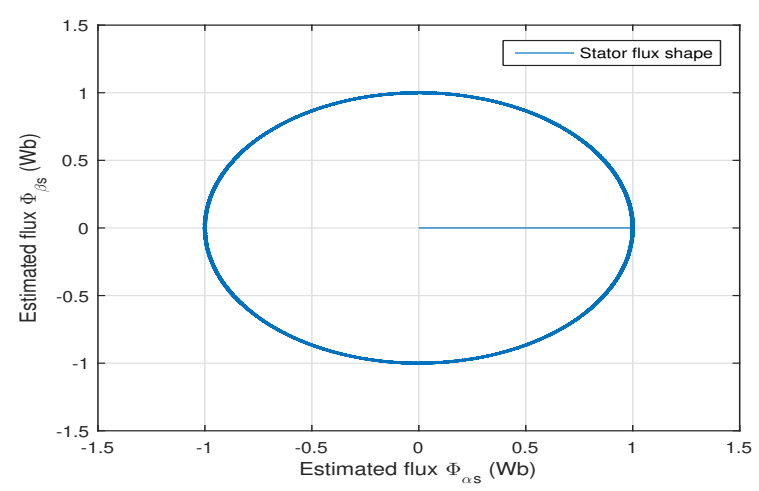

(h) Flux shape

Figure 14: Very low speed region

\section{Appendix}

Table 3 below lists the rated power and parameters of the used machine.

Table 3: IM drive rated power and parameters

\begin{tabular}{|c|c|}
\hline Rated power & $3 \mathrm{~kW}$ \\
\hline Voltage & $380 \mathrm{~V}$ \\
\hline Frequency & $50 \mathrm{~Hz}$ \\
\hline Pair pole & 2 \\
\hline Rated speed & $1440 \mathrm{rpm}$ \\
\hline Stator resistance & $2.2 \Omega$ \\
\hline Rotor resistance & $2.68 \Omega$ \\
\hline Stator inductance & $0.229 \mathrm{H}$ \\
\hline Rotor inductance & $0.229 \mathrm{H}$ \\
\hline Mutual inductance & $0.217 \mathrm{H}$ \\
\hline Moment of inertia & $0.047 \mathrm{~kg} . \mathrm{m}^{2}$ \\
\hline Viscous friction coefficient & $0.004 \mathrm{~N} . \mathrm{s} / \mathrm{rad}$ \\
\hline
\end{tabular}

\section{References:}

[1] G. Renukadevi and K. Rajambal, Modeling and analysis of multi-phase inverter fed induction motor drive with different phase numbers, WSEAS transactions on systems and control, 2013, vol. 8, no 3, pp. 73-80.

[2] I. Takahashi and T. Noguchi, A new quickresponse and high-efficiency control strategy of an induction motor, IEEE Transactions on Industry applications, 1986, no 5, pp. 820-827.

[3] M. Depenbrock, Direct self-control (DSC) of inverter fed induction machine, In IEEE Power Electronics Specialists Conference, 1987, pp. 632-641. IEEE.

[4] A. Sivaprakasam and J. D. Anunciya, A Survey on Matrix Converter fed Direct Torque Control Techniques for AC Machines, IETE Journal of Research, 2019, pp. 1-1.

[5] Y. Zahraoui, M. Akherraz and C. Fahassa, Induction motor DTC performance improvement by reducing torque ripples in low speed, UPB Sci. Bull. Ser. C, 2019, vol. 81, no 3, pp. 249260.

Volume 15, 2020 
[6] C. Fahassa, M. Akherraz and A. Bennassar, Sensorless DTC of an Induction Motor based on Intelligent Dual Observer and ANN based Selector Table, WSEAS transactions on systems and control, 2016.

[7] M. Bahloul, L. Chrifi-Alaoui, S. Drid, M. Souissi and M. Chaabane, Robust sensorless vector control of an induction machine using multiobjective adaptive fuzzy Luenberger observer, ISA transactions, 2018, vol. 74, pp. 144-154.

[8] A. Cheknane, K. Kouzi, H. Sayaf and I. Benhamida, Robust Speed Sensorless Fuzzy DTC Using Simplified Extended Kalman Filter for Dual-Star Asynchronous Motor (DSIM) with Stator Resistance Estimation, In International Conference in Artificial Intelligence in Renewable Energetic Systems, Springer, Cham, 2019, pp. 598-609.

[9] M. H. HOLAKOOIE, M. OJAGHI and A. TAHERI, Direct torque control of six-phase induction motor with a novel MRAS-based stator resistance estimator, IEEE Transactions on Industrial Electronics, 2018, vol. 65, no 10, pp. 7685-7696.

[10] S. Massoum, A. Meroufel, A. Bentaallah, F. Z. Belaimeche and A. Massoum, Sensorless Fuzzy Sliding Mode Speed Controller for Induction Motor with DTC based on Artificial Neural Networks, WSEAS transactions on power systems, 2016, vol. 11.

[11] A. Pal, G. D. Srivastava and R. D. Kulkarni, Simulation of Sensorless Speed Control of Induction Motor Using Direct Torque Control Technique Employing Five Level Torque Comparator and Twelve Sector Method, In International Conference on Nascent Technologies in Engineering (ICNTE), 2019, pp. 1-6. IEEE.

[12] H. Benbouhenni, Fuzzy speed controller of induction machine with 36 sectors DTC based ANFIS hysteresis comparator, Majlesi Journal of Mechatronic Systems, 2019, vol. 8, no 3, pp. 1-8.

[13] P. Manuprasad and K. B. Mohanty, Implementation of 12 Sector Fuzzy Controller for Direct Torque Control of Induction Motor, In Innovations in Power and Advanced Computing Technologies (i-PACT), 2019, pp. 1-6. IEEE.

[14] C. Stamate, Vector fuzzy integral, In Proceedings of the 11th WSEAS international conference on neural networks and 11th WSEAS international conference on evolutionary computing and 11th WSEAS international conference on Fuzzy systems, World Scientific and Engineering Academy and Society (WSEAS), 2010, pp. 221-224.

[15] P. Bergsten, R. Palm and D. Driankov, Fuzzy observers, In 10th IEEE International Conference on Fuzzy Systems.(Cat. No. 01CH37297). IEEE, 2001. pp. 700-703.

[16] Y. BO, (ed.), Fuzzy Sets, Fuzzy Logic, and Fuzzy Systems: Selected Papers by Lotfi A Zadeh, World Scientific, 1996.

[17] Y. Zahraoui, A. Bennassar, M. Akherraz and A. Essalmi, Indirect vector control of induction motor using an extended Kalman observer and fuzzy logic controllers, In 3rd International Renewable and Sustainable Energy Conference (IRSEC), 2015, pp. 1-6. IEEE.

[18] Y. Zahraoui, M. Akherraz, C. Fahassa and S. Elbadaoui, Induction motor harmonic reduction using space vector modulation algorithm, Bulletin of Electrical Engineering and Informatics, 2020, vol. 9, no 2.

[19] N. El Ouanjli, S. Motahhir, A. Derouich, A. El Ghzizal, A. Chebabhi and M. Taoussi, Improved DTC strategy of doubly fed induction motor using fuzzy logic controller, Energy Reports, 2019, vol. 5, pp. 271-279. 